\title{
Erratum to: Single cell analysis of CD4+ T cell differentiation reveals three major cell states and progressive acceleration of proliferation
}

\author{
Valentina Proserpio 1,3, Andrea Piccolo², Liora Haim-Vilmovsky ${ }^{1,3}$, Gozde Kar ${ }^{1}$, Tapio Lönnberg ${ }^{1,3}$, Valentine Svensson ${ }^{1}$, \\ Jhuma Pramanik ${ }^{1,3}$, Kedar Nath Natarajan ${ }^{1,3}$, Weichao Zhai ${ }^{4}$, Xiuwei Zhang ${ }^{1}$, Giacomo Donati ${ }^{5}$, Melis Kayikci, \\ Jurij Kotar ${ }^{4}$, Andrew N. J. McKenzie ${ }^{6}$, Ruddy Montandon ${ }^{3}$, Kylie R. James ${ }^{7}$, Daniel Fernandez-Ruiz ${ }^{8}$, William R. Heath ${ }^{8,9}$, \\ Ashraful Haque ${ }^{7}$, Oliver Billker ${ }^{3}$, Steven Woodhouse ${ }^{10,11}$, Pietro Cicuta ${ }^{4}$, Mario Nicodemi ${ }^{2 *}$ and Sarah A. Teichmann ${ }^{1,3^{*}}$
}

\section{Erratum}

After the publication of this work [1] it was noticed that four authors were omitted from the author list and author contributions.

These authors have now been added to the list, and the updated author contributions are included below.

\section{Authors' contributions}

VP, LHV, KNN, JP and TL carried out ex vivo/in vitro experiments. RM and KRJ carried out in vivo malaria experiments under the supervision of $\mathrm{OB}$ and $\mathrm{AH}$. VP, AP, VS, GK, GD, XZ, SW and MK performed data analysis. $\mathrm{AP}$ and MN carried out the mathematical modelling. DFR and WRH developed mouse model used in the study. AM provided mice and expertise on their use. WZ and JK carried out T-cell live imaging under the supervision of PC. VP, MN and SAT wrote the manuscript with contributions from all authors. SAT and MN supervised the work. All authors read and approved the final manuscript.

\section{Competing interests}

The authors declare that they have no competing interests.

\section{Author details}

${ }^{1}$ EMBL, European Bioinformatics Institute (EBI), Hinxton CB10 1SD, UK. ${ }^{2}$ Department of Physics, CNR-Spin, Istituto Nazionale di Fisica Nucleare (INFN), University of Naples Federico II, Napoli, Italy. ${ }^{3}$ Wellcome Trust Sanger Institute, Wellcome Trust Genome Campus, Hinxton, Cambridge CB10 1SA, UK. ${ }^{4}$ Cavendish Laboratory, University of Cambridge, Madingley Road,

\footnotetext{
*Correspondence: mario.nicodemi@na.infn.it; st9@sanger.ac.uk

${ }^{2}$ Department of Physics, CNR-Spin, Istituto Nazionale di Fisica Nucleare (INFN), University of Naples Federico II, Napoli, Italy

${ }^{1}$ EMBL, European Bioinformatics Institute (EBI), Hinxton CB10 1SD, UK
}

Cambridge CB3 OHE, United Kingdom. ${ }^{5}$ Centre for Stem Cells and Regenerative Medicine, Kings College London, London SE1 9RT, UK. ${ }^{6} \mathrm{MRC}$ Laboratory of Molecular Biology, Cambridge CB2 OQH, UK. ${ }^{7}$ QIMR Berghofer Medical Research Institute, Herston, Brisbane, Queensland, Australia.

${ }^{8}$ Department of Microbiology and Immunology, The Peter Doherty Institute for Infection and Immunity, University of Melbourne, Melbourne, Victoria Australia. ${ }^{9}$ The Australian Research Council Centre of Excellence in Advanced Molecular Imaging, The University of Melbourne, Parkville, Australia.

${ }^{10}$ Department of Haematology, Cambridge Institute for Medical Research, University of Cambridge, Cambridge Biomedical Campus, Wellcome Trust/ MRC Building, Hills Road, Cambridge CB2 OXY, UK. "'Wellcome Trust Medical Research Council Cambridge Stem Cell Institute, University of Cambridge, Cambridge, UK.

Received: 6 June 2016 Accepted: 6 June 2016

Published online: 22 June 2016

\section{Reference}

1. Proserpio V, Piccolo A, Haim-Vilmovsky L, Kar G, Lönnberg T, Svensson V, et al. Single cell analysis of $\mathrm{CD} 4+\mathrm{T}$ cell differentiation reveals three major cell states and progressive acceleration of proliferation. Genome Biol. 2016;17:103.

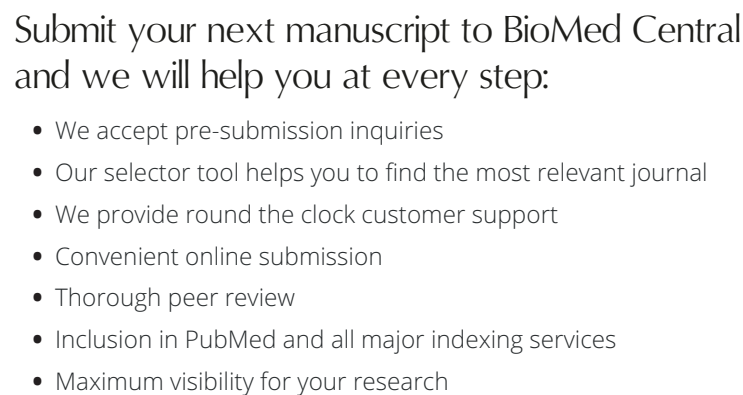

Submit your next manuscript to BioMed Central and we will help you at every step:

- We accept pre-submission inquiries

- Our selector tool helps you to find the most relevant journal

- We provide round the clock customer support

- Convenient online submission

- Thorough peer review

- Inclusion in PubMed and all major indexing services

- Maximum visibility for your research

Submit your manuscript at www.biomedcentral.com/submit 